\title{
Design Management
}

\author{
Ĺubica Knošková ${ }^{1}$
}

\begin{abstract}
The author analyzes in the paper the role of creativity and design in innovations, with emphasis on three theoretical models linking creativity, design and innovations. The effective use of design is linked to design management. The concept of design management relates to certain management activities, methods and skills that are required to optimize and manage design processes. The objective of Design management is the creation of synergy between the creative realm and the business realm. Factors influencing the level of design management are analyzed and suggestions for incorporating design as strategic function are outlined.
\end{abstract}

\section{Key words}

Design, product design, design management, innovation

JEL Classification: M10, M11, M30

\section{Introduction}

In considering design's strategic role there are two important trends of recent years to note: first, the design's role in differentiating products and services is of growing importance in a global market; second, the design's broader and subtler contributions to an organisation are increasingly understood, recognised and valued. But much business strategy literature predates or neglects these trends, and in the empirical literature of design management they are often discussed under the catch-all of 'strategic design'. Creativity and design are important features of a well-developed knowledge economy, not only for having a favourable impact on people's well-being and business performance, but also on innovation. (Stevens, Moultrie \& Crilly, 2008)

Design is a structured process that transforms creative ideas into concrete products, services and systems, (Swann \& Birke, 2005) and as such links creativity to innovation. As part of the innovation process, design has the potential to substantially contribute to the improving of the brand image, sales and profitability of a company. There is a general lack of quantitative indicators which directly measure creativity and design. Creativity is defined here as the generation of new ideas, but the number of ideas is an unobserved statistical phenomenon. For design activities there is more statistical evidence, but the number of indicators directly measuring design activities is limited. We therefore have to rely on proxy indicators, which only indirectly measure creativity and design. Creative skills are important for all economic sectors and activities and not only for the creative industries. The quality of the educational system, the desire of people to express themselves (artistically) and the openness of a society towards different countries and cultures are assumed to determine the Creative climate

1 Ing. L'ubica Knošková, PhD.; Ekonomická univerzita v Bratislave, Obchodná fakulta, Katedra tovaroznalectva a kvality tovaru, Dolnozemská cesta 1, 85235 Bratislava; E-mail: lubica.knoskova@euba.sk 
in a country. A more favourable Creative climate is assumed to result in more ideas, more creativity, which in turn should increase R\&D and design activities. R\&D and design not only develop further these ideas, but also shape them into commercially attractive new products and processes, thus increasing innovation. Higher levels of creativity are associated with increased levels of R\&D and design activities. Apparently more ideas create a larger and more diversified pool of potential research projects, tempting firms to increase their R\&D and design activities. The statistical results also show strong evidence of a positive link between increased R\&D and design performance and innovation, although innovation is also dependent on a range of other framework conditions. (Hollanders \& Van Cruysen, 2009)

Creativity and design have distinct roles in the innovation and the broader business performance context. Comercial success of products is driven by qualitative characteristics as quality, innovation degree, product and packaging design (Mlákay, 2004). The company product strategy influences the coordination of decisions on product lines, product mix, quality, design and services (Lacková \& Jurkovičová, 2008). Design has emerged as a key differentiator for businesses. As a result of the growing access to technology, firms increasingly have to compete at equal prices and functionality. Design increasingly assumes a new role as a competitive advantage and differentiator, creating new markets by linking technology with commercial and user considerations, whether linked to functionality, aesthetics, brand or other intangibles.

\section{Measuring Cerativity and Design}

In EIS Creativity and design report creativity is defined as the generation of new ideas; design is defined as the shaping (or transformation) of ideas into new products and processes; and innovation is defined as the exploitation of ideas, i.e. the successful marketing of these new products and processes. It should be emphasised that creativity, design and innovation and therefore not limited to certain sectors or professions, but apply across the economy. (Hollanders \& Van Cruysen, 2009)

Creativity and design can thus be linked to innovation. Creativity contributes to the expansion of available ideas and design contributes to increased chance of successfully commercialising these ideas. Swann and Birke carried out a study into the 'value and productivity impact of creativity and design in businesses, helping firms in Great Britain to identify how creativity can improve their performance (Swann \& Birke, 2005). They identified three different models linking creativity and design to innovation. In the linear mode/ creativity has a positive effect on R\&D which is turn has a positive effect on innovation (cf. the one-headed dashed arrows in Figure 1). The interactive mode/ not only includes feedback effects between the different elements of the linear model (cf. the two-headed full arrows in Figure 1) but also acknowledges the importance of design. Creativity relates directly with design and design relates directly with innovation. In the third and most complete model the creative climate takes a central position (cf. the two-headed dotted arrows in Figure 1). 
Figure 1 Three models for linking creativity, design and innovation

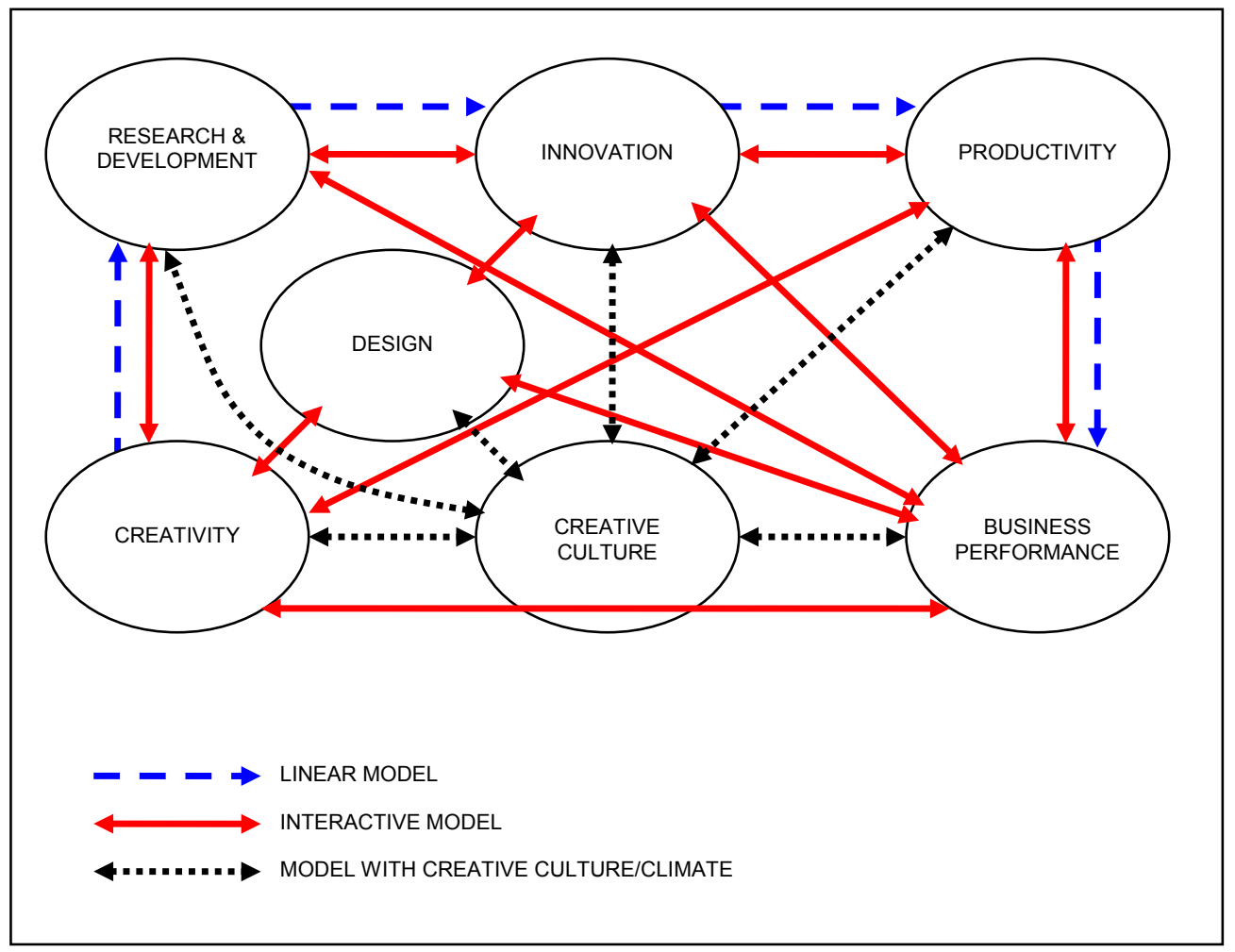

Source: Swann, P. \& D. Birke. (2005). Creativity, Design and Business Performance. DTI Economics paper, 15. p. 3

Following the European Innovation Scoreboard (EIS), a 'scoreboard approach' was adopted, using a large set of indicators to capture the different dimensions (European Innovation Scoreboard 2008) . Starting from a larger set of indicators, the results from a literature review and statistical data reduction analyses have resulted in a final set of 35 indicators which are classified in 7 different dimensions. Of these 7 dimensions, 3 capture performance in the Creative climate and 4 capture performance in Creativity \& design. The flow chart model in EIS 2008 Creativity and Design, is an adapted version of the third model placing more emphasis on the creative climate and allowing an interaction effect between R\&D and design.

In the scoreboard approach, the performance of an observed phenomenon is measured by using a set of indicators which grasp some of the key features of that phenomenon. Potential indicators, which are to be included in the analysis are identified based on a literature review and the indicators are then selected based on the results of both statistical analyses (correlation analyses and factor analyses) and what 'common sense' suggests would be the most directly relevant indicators. The quality of the educational system, the desire of people to express themselves (artistically) and the openness of the society towards different countries and cultures determine the Creative climate (Hollanders \& Van Cruysen, 2009). 
Figure 2 A "model" linking creativity, design and innovation

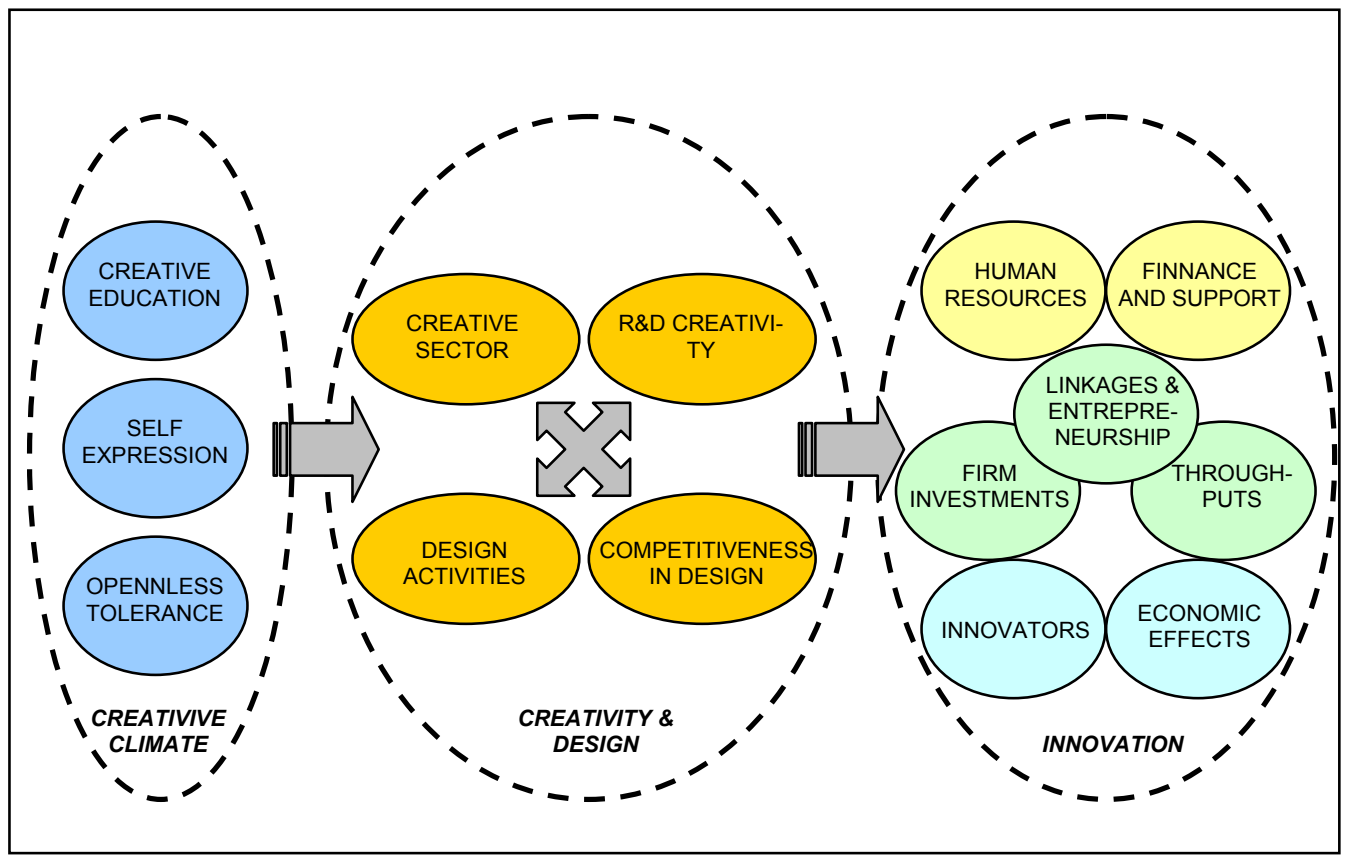

Source: Hollanders, H. \& Van Cruysen, A. (2009). Design, Creativity and Innovation: A Scoreboard Approach. Maastricht: Pro InnoEurope, p. 7.

In a more favourable Creative climate, the creation of new ideas is stimulated as people are better educated, have a stronger inclination to self expression and the creation of new ideas, and are being exposed more to new ideas and thoughts from both foreigners and other cultures within the same country. Creativity generates new ideas, so a more favourable Creative climate should increase creativity as it raises the number of ideas. More creativity will result in a stronger creative sector and higher levels of creativity in R\&D and design activities. We also introduce a dimension capturing the international competitiveness in design, to highlight the importance of design, both within the wider innovation process and as an economic sector. The flow chart is completed with the European Innovation Scoreboard (EIS) dimensions capturing enablers of innovation (Human resources and Finance and support), innovation at the firm level (Firm investments, Linkages \& entrepreneurship and Throughputs) and the Effects innovation (Innovators and Economic effects).

The statistical results show that there are strong relations between creativity, design and innovation. The best performing countries in creativity and design are the same countries - the innovation leaders and innovation followers - that show superior innovation performance in the EIS. Countries with a good creative climate tend to have higher levels of R\&D and design activities and also strong overall innovation performance. These findings point to the need to consider design and other non-R\&D activities as part of the broader approach to innovation policy as well as to the strong links between creativity and innovation. Creative education is the dimension which shows the strongest relation to innovation. This seems to suggest that policies aimed at improving levels of educational attainment and policies aimed at improving creative thinking in education will, after a number of years, have a positive effect on a society's in- 
novative performance. Effective use of design is a crucial enabler of competitiveness for many companies, but how well are companies actually doing when it comes to using this tool?

\section{Design management}

Effective use of design is closely linked to design management. The concept of design management relates to certain management activities, methods and skills that are required to optimize and manage design processes. This is dictated by the highly complex nature of the design process. As a professional field, design management focuses on a complex of all visual manifestations of companies, brands and products, as well as on non-visual aspects relating to the design process as such, or to processes for product development, production, distribution, sales, delivery or service. Another explicit objective comprises the creation of synergy between the creative realm and the business realm. These realms tend to operate with their own culture, own values and opinions, and their own dynamics. This disunity is perpetuated by management courses' lack of focus on design as a business tool, and design courses' lack of focus on business aspects, as these predominantly choose a cultural approach. As a result, design specialists' affinity for communication, marketing, and business strategy tends to fall short. Design management aims to connect these two realms, and bases itself on the idea that companies and organisations perform better when they manage to successfully harness and exploit the potential of design.

The European Commission considers design management to be a competence that comes under the umbrella of innovation management, in recognition of the fact that companies need innovation capability to be able to respond to new market opportunities and threats. Companies that invest in design tend to be more innovative and profitable, and grow faster than companies that do not. A string of recent studies show that design-driven companies do better in the area of innovation than others. And that innovation-driven companies see sooner design as a strategy than noninnovative companies. These studies also show that companies that deploy design on a strategic level, or as an internal process, are quicker to come up with new products than companies that do not have a design policy in place. The design-driven companies understand design as a resource and a way in which to build sustainable competitive advantage. In such companies, the scope of design management is broader and more process driven than it would be if it were used on a project-by-project basis. (Borja de Morzota \& Kim Young, 2009)

The assumption is that good design management practices in small and mediumsized enterprises lever a more effective use of design. This claim is substantiated by a recent study into the effects of design investment on business performance, and the role design management plays in that (Chiva \& Alegre, 2009).

We can assume following hypotheses on the results of design management:

- design management boosts business performance;

- investing in design is positively related to design management;

- design investments only influence business performance when the company has a design management structure in place; 
Design management has a positive effect on product design performance and process quality management. Good design and investment in design alone will not automatically make a company more successful. Design only bolsters business performance when it is the result of a well-managed process. The right skills are required to run an efficient and effective design process. Only then can design have a positive effect on business performance. Design management is becoming a commercial necessity, as it enables a company or organisation to successfully deploy design for innovation purposes, tailor to consumer needs, and realize benefit. When design management is an explicit part of management processes, it will have greater impact on business performance and help secure a market position for the long term.

Few academic papers have explicitly considered the design's place in the value chain. In one, Borja de Morzota finds design acts at three levels in the value chain, as simultaneously a differentiator, co-ordinator, and transformational process (Borja de Morzota, 2003):

- By optimizing the primary activities: design action on the consumer perceived value.

- By optimizing the coordination among functions and the support activities of the firm: design as a new function in the structure that transforms the management process.

- By optimizing the external coordination of the firm in its environment: design generating a new vision of the industry.

Understanding and creating perceived value draws on the core expertise of the designer, but quantifying it in Porter's terms is difficult when much is in the intangible values of good and services.

\subsection{The Design Management Staircase}

There is a range of design management aspects that can influence the way in which design is integrated and managed by a company - and therefore they have to be considered when defining a company's design management capability. In practice, companies handle design in many different ways. One important challenge we are facing is, therefore, to bring the main aspects of design management capability together in a coherent model. Based on the literature consulted, a model was put together: the Design Management Staircase. The DM Staircase uses an approach that is similar to the one the Danish Design Centre used in the development of its Design Ladder. Like the Design Ladder, the DM Staircase model is also a four-tier model, but a key difference lies in the fact, that the four tiers in the DM Staircase are defined on the basis of five factors, which makes the Design Management Staircase more specific and more detailed. The other difference is that is focussed on design management rather than simply the use of design (Koostra, 2009). 
Figure 3 Design Management Staircase

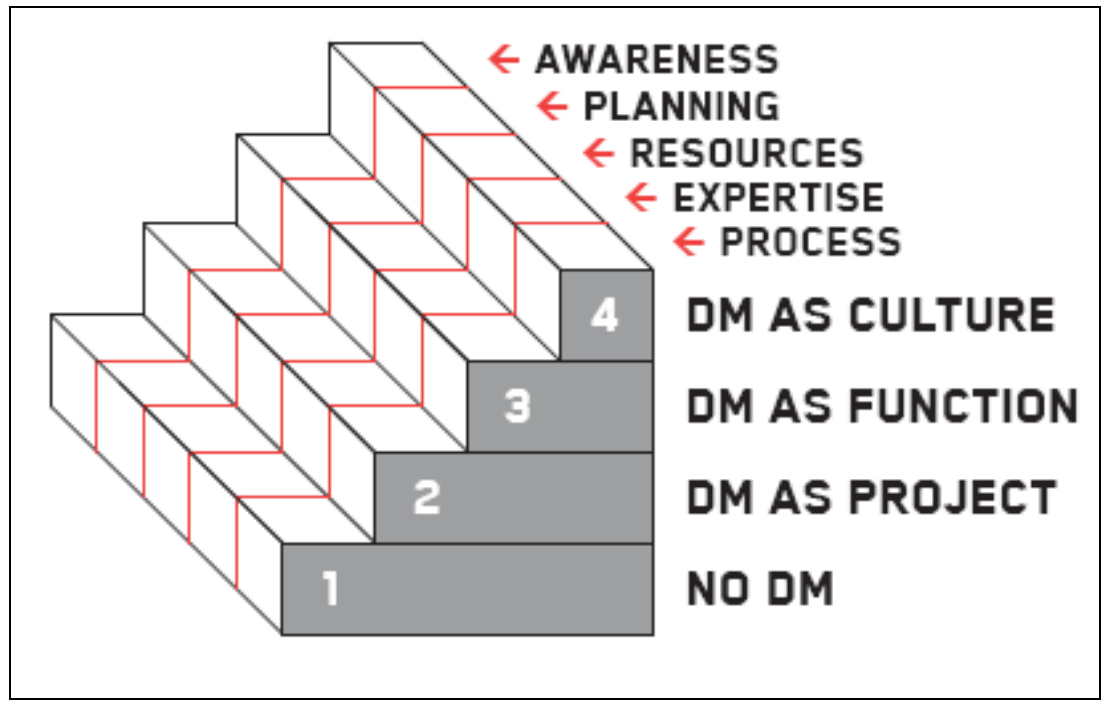

Source: Koostra, G. L. (2009). The Incorporation of Design Management in Today's Business Practices: An analysis of Design Management Practises in Europe. p. 12

The Design Management Staircase conveys companies' typical behaviour in the realm of design management on four levels. The specifications of these four levels of development are context-driven, but in principle range from immature to a level where design management is of a strategic nature and part of the company's culture. The staircase form of the model suggests that the higher a company makes it up onto the stairs, the greater the strategic importance of design at that company. The significance of the latter is highlighted by different studies that show that a company is more likely to grow when it deploys design in a strategic fashion (including Design Council, 2004, Danish National Agency for Enterprise and Housing, 2003).

The following describes the four levels of design management using a number of general characteristics (Koostra, 2009):

Level 1: No design management (some or no design activity; not repeated, defi ned or managed)

On this level, companies hardly pursue any active design policy, if at all. It may have just been implemented, or still used on an ad-hoc basis with limited targets and guidelines. There is little to no knowledge and experience available to handle design activities. Design plays no role or a limited role in the company's attempts to differentiate itself from its competitors. Possibly because the importance of differentiation is not understood, recognized or valued - or because the company is sceptical about design's potential added value.

\section{Level 2: Design management as project (design project management; repeated)}

This approach to design management is found at companies that make limited use of design, only to meet direct business needs. Design is deployed on a limited basis in ad-hoc style changes, product line extensions, or product improvement projects. At these companies, design is largely neglected as a significant tool for New Product Development (NPD) and innovation. Design is primarily used as a marketing tool, with 
a view to adding value to the existing product offering: through product appearance, styling, packaging, marketing communication, or visual identity. But design is not used to create added value through new products or services. As part of product development processes, design is merely used as a finishing touch at the end of the process. Coordination of design activities is minimal within a level 2 company. The responsibility for design activities is held at operational level. Experiences with design are only logged and shared on a limited scale within the organisation, mainly by a small group of directly involved employees.

Level 3: Design management as function (management of the design function, integrated with other processes; a defined role for design)

As soon as companies start linking the deployment of design to innovation and product development - at an early stage and structurally - their design efforts cease to only focus on the product and take a broader approach that includes the process. Innovation and the development of products and services call for the mobilisation of several disciplines and specialities, and require the company to synthesise an array of different factors. Companies with such an approach to design management will have a dedicated employee or department with formal responsibility for the management of the total design process in the organisation. This person or department will act as an interface between different kinds of design specialists, departments and company management. In order to accommodate shortening product cycles, design is used proactively, and product development becomes a permanent feature. One critical success factor is time-to-market; project turnaround from the initial idea to product launch. Process quality is an important factor to ensure a company keeps up with the competition.

Level 4: Design management as culture (strategic management of design; design leadership; infused)

This approach to design management can be found at companies that are looking to establish themselves as a market leader through design innovation. This refers to non-technological innovations that are first to market, as opposed to so-called me-too innovations, where design innovations are copied by followers. Design innovation can come in the form of new products or services, an innovating communication/ presentation style, or innovating marketing tactics, such as a new retail concept. These companies are highly design-driven. They stand out because they have a differentiation strategy that has design at its core. This approach is often also adopted by start-ups that are founded on innovation. In order to be able to excel, both senior management and the different departments are closely involved with design, and design is part of the company's main business processes. These kinds of companies also manage to instil awareness of and commitment to the importance of design in their employees. This will probably lead - when design has trickled into the fabric of the company and become part of corporate culture - to the most successful and broadest use of design. Design is in such cases a way of life within the organisation.

The staircase model could lead people to believe that the highest tread is always the one to aim for, but not every company will need to focus its strategy on the role of design as a driving force for innovation. Depending on their nature, market position, or strategy, a level 2 or level 3 approach may well suffice. Still, most companies cannot afford to neglect design management altogether, as in the case of companies stuck on 
the first tread of the staircase model (possibly except for local, small-scale very specialist providers).

Three ways design can be strategic. It can be seen that from many of the various strategy viewpoints, design can play a valuable role, with common themes emerging from this examination. Design expertise can contribute (Stevens, Moultrie \& Crilly, 2008):

- in conceiving and creating high-value products;

- $\quad$ in building product (or brand) differentiation and customer intimacy;

- as an integrator and mediator between professional domains, both within the organisation (e.g. marketing, production) and outside (e.g. suppliers, distributors, partners);

- as a hard-to-imitate tacit knowledge resource;

- in shaping, communicating and reinforcing an organisation's internal culture;

- in exploring uncertainty and assessing trade-off, through prototyping and visualisation;

- in stimulating creativity and providing fresh perspectives in the strategy context.

It is suggested then that design's strategic relevance can be considered in three ways: competing by 'high design' can be a strategic position in itself; an integrated, coherent design approach can help implement strategic positioning; design methods (so-called 'design thinking') can inform strategy formulation. Tim Brown from IDEO, autor of term design thinking puts design role in the middle of new business model of creative organization for 21 century (Brown, 2007).

\subsection{Factors Influencing the Level of Design Management}

In order to get a clearer idea of what the four levels of design management entail, five factors based on an extensive literature search were identified. These factors appear to bear upon the success and failure of design, making them indicators for good design management. Each factor is represented in each of the four DM levels. The following gives brief explanations of each factor (Koostra, 2009):

Factor 1: Awareness of benefits The extent to which a company (and its management in particular) is aware of the benefits and potential value design and design management can offer.

Factor 2: Process The extent to which a company pursues a robust and effective design management process, embedded into its core business processes.

Factor 3: Planning The extent to which a company has developed a strategy for design, articulated in business plans, and communicated widely.

Factor 4: Expertise The quality of the staff (level of experience, skills, and knowledge) and the range of tools and methods applied.

Factor 5: Resources The extent to which a company invests in design projects and deploys an appropriate design staff. Also if it invests in a creative working environment, hard- and software for design, etc. 
The outcome of the study also shows that companies that make it high onto the DM Staircase report greater turnover increases in the past five years. Sometimes even by over $25 \%$. Investing in design therefore seems to bear fruit. It should, however, still be noted that design management is not the only factor that can positively influence a company's turnover. The study does uncover positive correlation between DM rating and business performance, although causal links have yet to be determined. While design possibly breeds success, it could also be that more successful companies tend to invest more heavily in design - and with that develop greater capability for the effective management of design.

\section{Conclusion}

First, the research of Chiva and Alegre provides empirical evidence that design management enhances firm performance, supporting H3. Design management is considered as the organizational and managerial skills that allow a company to develop good and efficient designs, and recently the latter has been empirically related to firm performance. Second, the present research also provides empirical evidence that investing in design is positively related to design management, sustaining $\mathrm{H} 2$. This is probably because to improve design management skills, financial resources are required. However, it does not seem to be the only reason for the enhancement of these skills. Other organizational, cultural, or strategic factors might also be essential if design management skills are to increase. On the other hand, design investment is used not only to improve design management skills but also to acquire new designs from external designers or to buy hardware or software for designing, among others. Consequently, it is important to emphasize that simple design investment do not imply improvement in design management skills. Furthermore, although high investment in design might improve skills, it also seems true that higher skills usually justify additional investment in design. Companies invest in design and consequently improve design management skills. This improvement increases design effectiveness. Because of this, these companies invest more in design, as they feel it is a source of competitive advantage. Consequently, this might imply the existence of a virtuous cycle between design investment and design management. Third, design investment has an indirect positive effect on firm performance, mediated by design management, supporting $\mathrm{H} 1$. Therefore, design management seems to play an essential role when investing in design. Companies that manage design effectively and efficiently attain better performance than those that do not. It is important to emphasize the importance of design management versus simple design investment.

In Slovakia, the study on relationship of design management and design performance is missing, which opens the space for interdisciplinary research and education.

\section{References}

Borja de Mozota, B. \& Kim Young, B. (2009). Managing Design as a Core Competency: Lessons from Korea. Boston: Desing management Institute. Retrieved March 15, 
2011 from

http://www.logroscreativos.com/docs/managing_design_as_a_core_competency_ lessons_from_korea.pdf

Borja de Mozota, B. (2003). Design and Competitive Edge: A model for design management excellence in European SME. Retrieved March 15, 2011 from http://bura.brunel.ac.uk/bitstream/2438/1387/1/Design\%20and\%20Competitive \%20Edge.pdf

Brown, T. (2007). The Challenges of Design Thinking. In Design Council Conference Intersections. Retrieved February 12, 2011 from http://www.designcouncil.org.uk/resources-and-events/Designers/Intersections071/The-challenges-of-design-thinking/

European Commision (2009). European Innovation Scoreboard 2008: Comparative analysis of Innovative Performance. Luxemburg: Office for Official Publications of the European Communities.

Hollanders, H. \& Van Cruysen, A. (2009). Design, Creativity and Innovation: A Scoreboard Approach. Maastricht: Pro InnoEurope.

Chiva, R. \& Allegre, J. (2009). Investment in Design and Firm Performance: The Mediating Role of Design Management. The Journal of Product Innovation Management, 26, 424-440.

Koostra, G. L. (2009). The Incorporation of Design Management in Today's Business Practices: An analysis of Design Management Practises in Europe. Retrieved March 17, 2011 from http://database.designmanagementeurope.com/uploads/case/71/370.pdf

Lacková, A. \& Jurkovičová, L. (2008). Systémové inžinierstvo kvality: Kvalita $v$ produktovej stratégii. Bratislava: Vydavatel'stvo Ekonóm.

Mlákay, J. (2004). Produkt a konkurencia. Bratislava: Vydavatel'stvo Ekonóm.

Stevens, J., Moultrie, J. \& Crilly, N. (2008). Designing and design thinking in strategy concepts: frameworks towards an intervention tool. In International DMI Education Conference Design Thinking: New Challenges for Designers, Managers and Organizations 14-15 April 2008. ESSEC Business School, Cergy-Pointoise, France University of Cambridge.

Swann, P. \& Birke, D. (2005). Creativity, Design and Business Performance. DTI Economics paper, 15, 76. Retrieved February 15, 2011 from http://www.scribd.com/doc/2529704/Creativity-Design-and-Businessperformance 